\title{
PERFORMANCE TRADE-OFFS AMONG TROPICAL TREE SEEDLINGS IN CONTRASTING MICROHABITATS
}

\author{
Christopher Baraloto,,${ }^{1,3}$ Deborah E. Goldberg, ${ }^{1}$ And Damien Bonal ${ }^{2}$ \\ ${ }^{1}$ Department of Ecology and Evolutionary Biology, University of Michigan, Ann Arbor, Michigan 48109-1048 USA \\ ${ }^{2}$ Unite Mixte de Recherche (UMR) "Ecologie des Forêts de Guyane," Institut National de la Recherche Agronomique
} (INRA) Kourou, French Guiana

\begin{abstract}
We investigated performance trade-offs among seedlings of nine tropical tree species during a five-year field experiment. Seedlings were grown in eight microhabitat types composed of paired gap and shaded understory sites in each of four soil types.

We defined performance trade-offs relevant to coexistence as significant pairwise rank reversals for species performance between contrasting situations, of which we characterize three types: microhabitat, fitness component, and ontogenetic. Only 2 of 36 species pairs exhibited microhabitat trade-offs or reversed rankings for survival or relative growth rate (RGR) among microhabitats, and only one species pair reversed performance ranks among soil types. We found stronger evidence for rank reversals between fitness components (survival and RGR), particularly in gap vs. understory environments, suggesting a general trade-off between shade tolerance (survival in shade) and gap establishment (RGR in gaps). Third, the most frequent rank reversals between species pairs occurred between early and later ontogenetic stages, especially between fitness components in contrasting microhabitats. Overall, 15 of 36 pairs of potentially competing species exhibited some type of seedling performance trade-off, two species pairs never outperformed one another, and for 19 species pairs one species was a consistent better performer. We suggest that ontogenetic trade-offs, in concert with microhabitat and fitness component trade-offs, may contribute to species coexistence of long-lived organisms such as tropical trees.
\end{abstract}

Key words: canopy gaps; French Guiana; regeneration niche; relative growth rate; seed size; shade tolerance; soil moisture; tropical forest.

\section{INTRODUCTION}

An ecological trade-off occurs when a higher fitness under one set of conditions causes a reduction in fitness under another set of conditions (MacArthur and Levins 1964). The theoretical importance of performance trade-offs in community ecology is widely accepted, either to determine constraints on organismal morphology or physiology (Poorter 1999, Walters and Reich 1999), or to understand interspecific differences that contribute to community structure (Grime 1979 , Givnish 1988, Tilman 1988, Latham 1992, Huston 1994). However, much less attention has been paid to the critical empirical problem of how to actually identify trade-offs that could potentially contribute to coexistence (Kitajima and Bolker 2003, Kneitel and Chase 2004); in this paper, we address two central issues that we argue have been underemphasized.

The first issue concerns identification of trade-offs contributing to coexistence in a multi-species community. Theory predicts that a necessary, although not always sufficient, condition for coexistence is that each

Manuscript received 24 December 2004; revised and accepted 31 January 2005; final version received 25 February 2005. Corresponding Editor: B. Shipley.

${ }^{3}$ Present address: UMR "Ecologie des Forêts de Guyane,' INRA Kourou, BP 709, 97387 Kourou Cedex, France. E-mail: baraloto.c@kourou.cirad.fr species outperforms each of the others in some situation (e.g., identity of limiting resource, resource level, microenvironment, predator occurrence) that varies in space or time in that community (MacArthur and Levins 1964, Chesson 1985). These conditions necessarily imply a reversal in rank of performance among species between situations (McPeek 1996, Chase and Leibold 2003, Kneitel and Chase 2004). In a plot of performance in one situation against performance in a second situation, rank reversals between two species appear as a negative correlation, and trade-offs have often come to be defined operationally as such negative correlations (Stearns 1992, Kitajima and Bolker 2003). However, when dealing with more than two species, Fig. 1 demonstrates that the existence of a significant negative correlation in performance of species between two situations does not necessarily mean that each species will outperform each of the others in at least one situation. Both scenarios 1 and 2 represent correlationtype trade-offs even though many species pairs in scenario 2 fail to meet the criterion of rank reversals between the two situations. Only the extreme case illustrated in scenario 1 adheres to the pairwise reversal definition of a multiple-species trade-off. The correlations approach to defining trade-offs may be more appropriate for identifying general trends among traits 

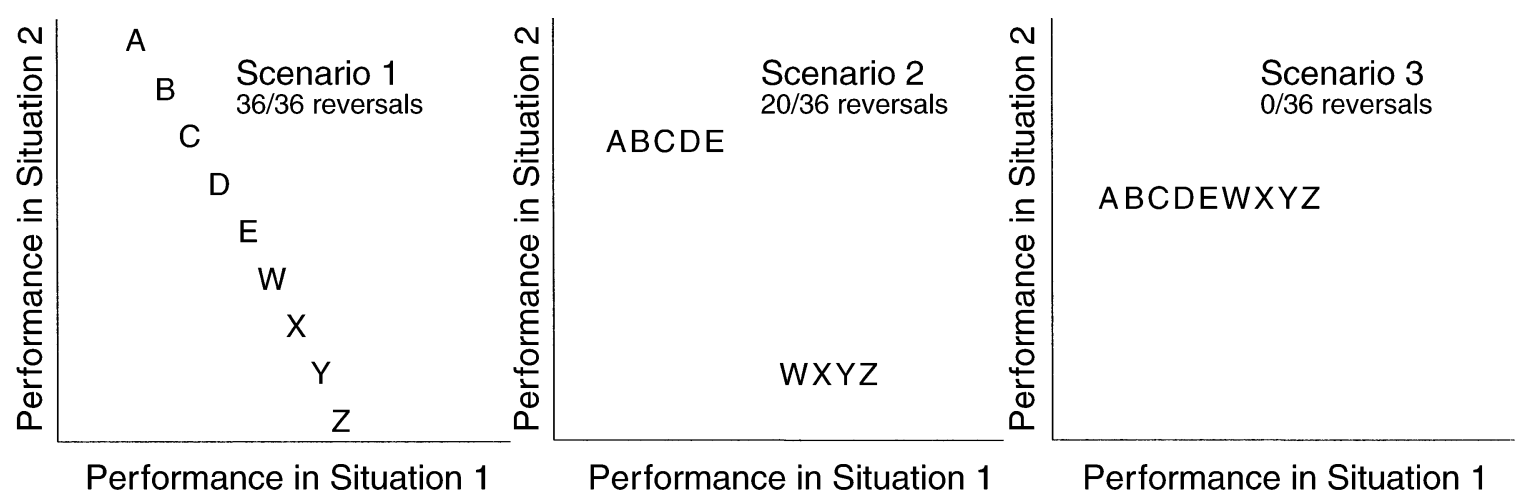

FIG. 1. A conceptual framework for understanding performance trade-offs in multiple-species communities. The three scenarios illustrate the performance of nine species (depicted as capital letters) in two contrasting situations. Shown in each panel are the proportion of (36 possible) species pair combinations exhibiting rank reversals in performance between the two axes. See Methods: Statistical analyses for a definition of "situations."

underlying fitness differences among many species (e.g., Wright et al. 2004).

The second important issue that we argue has been little emphasized to date is the occurrence in nature and potential contribution to coexistence of different types of trade-offs. In particular, we identify three types: microhabitat trade-offs, fitness component tradeoffs, and ontogenetic trade-offs. While the contributions of some of these to coexistence (especially microhabitats) are well understood, the consequences of other types of trade-off are less clear, but also potentially quite important.

\section{Microhabitat trade-offs}

For plants, partitioning in the relative quantities of resource needed will mostly (but not entirely [Tilman 1982]) be reflected by differential performance in microhabitats with different limiting resources. Several theoretical models for community structure invoke microhabitat trade-offs and predict that certain species will dominate at given positions along a multivariate environmental gradient, because of either differences in competitive ability for the most limiting resource at that point (Tilman 1988, 1994), or differences in species' positions along a growth rate/stress tolerance continuum (Grime 1977, 1979). As a result, species performance rankings for some fitness component (e.g., survival or growth) are predicted to shift along microhabitat gradients (Tilman 1990, Suding and Goldberg 2001). To the extent that communities are heterogeneous in space, such rank reversals in response to microhabitat can lead to coexistence (Tilman 1982, Kneitel and Chase 2004). Because microhabitats can be characterized using different resource or physical factor axes, microhabitat trade-offs might be further subdivided; we group them here for simplicity.

\section{Fitness component trade-offs}

Trade-offs might also occur based on the means by which differential performance is effected (Kitajima and Bolker 2003). The most common fitness component trade-off involves species with higher survivorship exhibiting lower maximum relative growth rate (RGR) (Latham 1992, Kitajima 2002, Schiesari 2004). The consequences of fitness component trade-offs for coexistence have not yet been explored, except for the special case of an interaction between fitness component trade-offs and microhabitat trade-offs. For example, shade tolerance is regularly interpreted to result from a trade-off between survival in low light conditions and RGR in high light conditions (Kitajima 1994, Walters and Reich 1996, 1999, Davies 2001, Dalling and Hubbell 2002). The general case of a trade-off between high survival at low resources vs. high growth at high resources can lead to "nonlinearities" in relative fitness that promote coexistence in spatially or temporally heterogeneous environments (Armstrong and McGehee 1980, Chesson 2000).

\section{Ontogenetic trade-offs}

A third type of performance trade-off involves changes in species' performance rankings for the same fitness component across developmental stages in an organism's life history. Size-dependent shifts in reaction norms for individual species may result in performance rank reversals between species, even for the same fitness component in the same microhabitat (McConnaughay and Coleman 1999, Lusk 2004). The contribution of ontogenetic trade-offs to community structure has not been dealt with explicitly. However, their existence may indicate the limitations of current data sets for defining the lifetime fitness parameters used in many theoretical models and underline the need for age- or stage-structured models for community structure (Chave 2004, Kneitel and Chase 2004). Clearly, ontogenetic trade-offs are especially likely for longlived perennial organisms such as trees, as they present several life history stages for which performance may vary (Canham and Marks 1985, Clark and Clark 1992). However, because identification of ontogenetic trade- 
TABLE 1. Summary of traits for the focal species used in the field experiment.

\begin{tabular}{|c|c|c|c|c|c|c|c|}
\hline Species & Family & $\begin{array}{l}\text { Dry seed } \\
\text { mass }(g) \dagger\end{array}$ & $\begin{array}{l}\text { Initial } \\
\text { seedling } \\
\text { height } \\
(\mathrm{cm}) \ddagger\end{array}$ & $\begin{array}{c}\text { Initial } \\
\text { seedling } \\
\text { mass }(\mathrm{g}) \S\end{array}$ & $\begin{array}{c}\text { Seedling } \\
\text { transplant } \\
\text { age } \\
\text { (weeks) }\end{array}$ & $\begin{array}{l}\text { Cotyledon } \\
\text { position }\end{array}$ & $\begin{array}{l}\text { Cotyledon } \\
\text { function }\end{array}$ \\
\hline Goupia glabra & Goupiaceae & 0.0015 & 4.7 & 0.01 & 8 & epigeal & foliar \\
\hline Jacaranda copaia & Bignoniaceae & 0.028 & 6.3 & 0.07 & 3 & epigeal & foliar \\
\hline Qualea rosea & Vochysiaceae & 0.096 & 11.2 & 0.24 & 6 & epigeal & foliar \\
\hline Recordoxylon speciosum & Caesalpiniaceae & 0.21 & 11.5 & 0.10 & 2 & hypogeal & intermediate \\
\hline Dicorynia guianensis & Caesalpiniaceae & 0.35 & 12.1 & 0.14 & 2 & epigeal & reserve \\
\hline Sextonia rubra & Lauraceae & 1.18 & 20.3 & 0.70 & 4 & hypogeal & reserve \\
\hline Virola michelii & Myristicaceae & 1.24 & 13.2 & 0.41 & 2 & epigeal & reserve \\
\hline Eperua falcata & Caesalpiniaceae & 4.23 & 21.2 & 3.64 & 2 & hypogeal & reserve \\
\hline Eperua grandiflora & Caesalpiniaceae & 27.4 & 33.5 & 26.7 & 2 & hypogeal & reserve \\
\hline
\end{tabular}

$\dagger$ Dry seed mass corresponds to the mean of 30-50 groups of seeds for small-seeded species $(<0.1 \mathrm{~g}), 30-50$ seeds for species of intermediate size $(<3 \mathrm{~g})$, and the estimated dry mass for larger seeds planted in the experiment, for which wet mass was measured.

$\ddagger$ Mean height of seedlings transplanted into the field experiment at $2-4$ weeks of age ( $n=288$ seedlings per species).

$\S$ Mean dry mass of 30 seedlings from among those transplanted into the shadehouse experiment at $2-8$ weeks of age, including remaining seed reserves.

offs requires long-term data from field observations or experiments, few studies have examined their occurrence, especially relative to microhabitat and fitness component trade-offs.

Although an evaluation of these three types of tradeoffs for multiple species would provide insight into mechanisms of coexistence in any community of potential competitors, it is of particular relevance in tropical forests. Tropical forests are among the most species-rich plant communities described, and tropical trees comprise a large gradient in morphological and ecophysiological attributes (Hammond and Brown 1995, Grubb and Metcalfe 1996, Bonal et al. 2000a), some of which change with ontogeny (Poorter 1999, Baraloto 2001, Sack et al. 2002). Given the remarkable diversity of microhabitat conditions that has been observed in tropical forests (e.g., Nicotra et al. 1999), such trait variation has been suggested to reflect adaptive differentiation to microhabitats characterized by particular environmental conditions, including resource availability (Grubb 1977, Ricklefs 1977, Burslem 1996, Grubb 1996). Yet the contribution to community organization of shifts in performance hierarchies along resource gradients remains a subject of debate (Hubbell et al. 1999, Brokaw and Busing 2000).

In this paper, we assess the frequency of microhabitat, fitness component, and ontogenetic trade-offs among nine sympatric canopy tree species from French Guiana grown in a five-year field experiment. First, we assess the evidence for differential performance among species in microhabitats representing the range of light, soil moisture, and soil nutrient conditions found in this lowland tropical forest. Second, we examine whether fitness component trade-offs between growth rate and survival occur within and among microhabitat types. In particular, we test the predicted rank reversals between survival in low-resource environments and growth in high-resource environments. Finally, we determine if species reverse ranks between two well-de- fined intervals in the experiment. We discuss the performance advantages to species with particular suites of traits across the resource gradient, and the implications of the identified trade-offs for the community structure of this tropical forest.

\section{Methods \\ Study site}

The study was conducted in the Paracou Reserve $\left(5^{\circ} 18^{\prime} \mathrm{N}, 52^{\circ} 55^{\prime} \mathrm{W}\right)$, a lowland tropical rain forest near Sinnamary, French Guiana. The site receives $>60 \%$ of the annual $3160 \pm 161 \mathrm{~mm}$ of precipitation (mean \pm $\mathrm{SE}$ ) between mid-April and mid-June, and $<50 \mathrm{~mm} / \mathrm{mo}$ in September and October (Bonal et al. 2000b). The soil structure of the reserve is heterogeneous, and four soil types can be identified in the field that correspond broadly to topographic position and texture. Few sharp ridges occur across the landscape, and the relatively flat plateaus can be characterized as white sand (podzol) or clay (plateau) soils. Midslope from clay plateau sites are clay soils with superficial drainage (slopes). Seasonally inundated sites characterize areas of the lowest topography, which we have grouped here as swamp soils. These four soil types represent contrasting conditions of nutrient availability and soil moisture (see Appendix A). At one extreme are the midslope soils, where both nutrient availability and soil moisture are low. At the other extreme are swamp forest soils, where both nutrient availability and soil moisture are high.

\section{Species}

Seeds were collected from nine sympatric species of canopy trees from January to March, 1999. The nine focal species were chosen to represent the range of seed and seedling size among tree species from the Paracou reserve (Table 1; Baraloto 2001).

To control for the influence of maternal effects or local adaptation, more than 50 seeds were collected 
from within a $10 \mathrm{~m}$ radius of each of at least six adult trees per species; when transplanted, seedlings were chosen at random with respect to maternal source. All germinating seedlings were kept for at least two weeks in germination boxes ( $50 \mathrm{~cm}$ deep) containing homogenized forest soil, in a shaded understory site. For the larger seeded species (Eperua falcata and Eperua grandiflora), seeds were weighed prior to germination.

\section{Experimental design}

The field experiment was designed to investigate performance along the complete gradient of resources present in the forest. Because soil resources to which seedlings respond are more likely to comprise continuous gradients along which the four soil types we identified are distributed, we used a split-plot design for the experiment, in which replicate sites within a soil type were chosen and used as random effects nested within soil type in the analyses. To determine how species responses to soil resources interact with light availability, we included both gap and understory plots within each planting site.

In January 1999, we located 36 recently formed light gaps of small to medium size (50-200 $\mathrm{m}^{2}$ ) across the Paracou landscape. At each site, a $1.5 \mathrm{~m}$ deep soil core was taken to determine soil type using color and texture analysis of $20-\mathrm{cm}$ horizons. Based on these cores and measurements of gap size, 24 gaps were chosen, 6 on each of the four soil types described in Appendix A. In addition, we established understory plots $25 \mathrm{~m}$ from each gap where color and texture results from $1.5-\mathrm{m}$ soil cores were similar to those from the paired gaps. Thus, within each soil type were six planting sites, each consisting of a pair of gap and understory plots. Environmental characterization of the plots is given in Appendix A.

In February 1999, a triangular exclosure $2.3 \mathrm{~m}$ on each side was established in each of the 48 plots using wire cages of $1-\mathrm{cm}$ mesh to a height of $1 \mathrm{~m}$, within which all vegetation was removed. The exclosure was bent and staked at the soil surface to discourage mammalian predators such as Agouti paca, Dasyprocta leporina, and Myoprocta acouchi, which harvest remaining seed reserves, or Mazama spp., which graze young seedling stems. In April 1999, we transplanted six individuals of each of the nine focal species into each plot ( $n=288$ individuals per species). The initial planting density of 23.5 individuals $/ \mathrm{m}^{2}$ represents the maximum observed juvenile density in this forest (18.5 \pm 7.9 stems $<100 \mathrm{~cm}$ tall per $\mathrm{m}^{2}$ [mean $\pm \mathrm{SD}$ ]; C. Baraloto and J.-F. Molino, unpublished data). Seedling age at planting varied among species, from two to eight weeks depending on fruiting phenology and germination delay (Table 1). The stem length of all individuals was measured at the planting date as the initial height. Individuals that died within the first two weeks after planting were replaced. All individuals were censused eight times during a 54-month period from the planting date. At each census, mortality was noted in addition to measurements of height, leaf number, and leaflet number.

\section{Statistical analyses}

We used different models to evaluate the growth and survival components of seedling fitness through time. For survival, we examined the effects of species, gap treatment, and soil type using a split-plot partially nested mixed-model analysis of variance (ANOVA) with repeated measures. To account for variability of planting sites within soil types, we included planting site (6 gap-understory pairs per soil type) in the models as a random effect, nested within soil type. This model was appropriate for measures of survival, where differences among sites might occur that are related to site conditions that we did not measure (e.g., presence of insect predators or pathogens). However, for growth response, the environmental descriptions we made were more likely to allow us to partition variance between sites than the simple nested effect. Here we used an ANCOVA model on the dependent variable of seedling height, with the measures of light, soil phosphate, and soil moisture for each plot included as covariates. In this way, we also tested for the overall effect of a given resource on species' response. In both models, the eight census intervals were included as repeated measures, with the real time of the census measurement included in the model.

Our initial examination of the data revealed two time periods between which seedling performance changed consistently among species, with mortality decreasing and seedling height increasing markedly. These patterns reflected the age at which seed reserves had been exhausted for even the larger seeded species, as well as a point during which lateral extensions of stems and roots has been observed for several of the focal species in separate trait screenings (Baraloto 2001). We thus distinguished two ontogenetic stages in the experiment, an early seedling stage from 0 to 18 months, and a later stage from 18 to 54 months. For each stage, we calculated the proportion survival in a site as well as the relative height growth rate (centimeters per centimeter per year) of each surviving individual after Hunt (1978) as

$$
\mathrm{RGR}=\frac{\ln \left(\text { height }_{\text {final }}\right)-\ln \left(\text { height }_{\text {init }}\right)}{\text { time }_{\text {final }}-\text { time }_{\text {init }}} .
$$

We identified performance trade-offs using pairwise comparisons among species across the 32 microhabitat $\times$ fitness component $\times$ ontogenetic stage situations. Our conceptual model predicts that coexistence of particular species pairs is promoted if each species outperforms the other in at least one situation (a rank reversal; Fig. 1). Under this model, any pairwise rank reversal is determined to be biologically significant if the evidence for it is statistically significant when accounting for multiple comparisons. Accordingly, we assessed whether each species significantly outper- 
TABLE 2. Summary of split-plot ANOVA for survival in the field experiment.

\begin{tabular}{|c|c|c|c|}
\hline Source & df & MSE & $F$ \\
\hline \multicolumn{4}{|l|}{ Between subjects } \\
\hline Species & 8 & 26.03 & $54.8 * * *$ \\
\hline Gap & 1 & 72.16 & $51.1 * * *$ \\
\hline Soil type & 3 & 5.36 & 2.97 \\
\hline Species $\times$ gap & 8 & 3.21 & $7.99 * * *$ \\
\hline Species $\times$ soil type & 24 & 1.44 & $3.04 * *$ \\
\hline Gap $\times$ soil type & 3 & 2.09 & 1.48 \\
\hline Species $\times$ gap $\times$ soil type & 24 & 0.36 & 0.90 \\
\hline Site(soil type) & 20 & 1.81 & $4.50 * * *$ \\
\hline Species $\times$ site $($ soil type $)$ & 160 & 0.48 & 1.18 \\
\hline Gap $\times$ site $($ soil type $)$ & 20 & 1.41 & $3.52 * * *$ \\
\hline Error & 159 & 0.40 & \\
\hline \multicolumn{4}{|l|}{ Within subjects } \\
\hline Months & 7 & 32.81 & $425.5^{* * *} *$ \\
\hline Months $\times$ species & 56 & 0.69 & $19.0 * * *$ \\
\hline Months $\times$ gap & 7 & 1.67 & $30.6 * * *$ \\
\hline Months $\times$ soil type & 21 & 0.26 & $3.37 * * *$ \\
\hline Months $\times$ species $\times$ gap & 56 & 0.15 & $4.59 * *$ \\
\hline Months $\times$ species $\times$ soil type & 168 & 0.06 & $1.55^{* * *}$ \\
\hline Months $\times$ gap $\times$ soil type & 21 & 0.04 & 0.78 \\
\hline Months $\times$ species $\times$ gap $\times$ soil type & 168 & 0.03 & 0.88 \\
\hline Months $\times$ site(soil type) & 140 & 0.08 & $2.34 * * *$ \\
\hline Months $\times$ species $\times$ site $($ soil type $)$ & 1120 & 0.04 & 1.10 \\
\hline Months $\times$ gap $\times$ site $($ soil type $)$ & 140 & 0.05 & $1.66 * * *$ \\
\hline Error & 1113 & 0.03 & \\
\hline
\end{tabular}

formed the other under each of the 32 situations using Wilcoxon's $Z$ statistic with a probability level set to 0.95, with Bonferroni adjustment. For each species pair in each situation, we tested the null hypothesis of equivalent performance across the six replicate plots of a given situation.

The types of performance trade-offs occurring for each species pair were identified by the situational axes across which any rank reversals were observed. Microhabitat trade-offs were identified as rank reversals for a given measure of performance (survival, RGR) between any combination of gap and soil type. Fitness component trade-offs were identified as rank reversals between survival and RGR. Ontogenetic trade-offs were identified as rank reversals between early and later stages. We also identified trade-offs involving interactions between the three types. For example, rank reversals between survival in one microhabitat and growth in another would be a microhabitat $\times$ fitness component trade-off.

\section{RESUlTs}

For survival, species responded significantly differently to soil types, even when the variation of sites within soil types was accounted for (Table 2; Appendix B: Fig. B1). Dicorynia guianensis and Eperua grandiflora had similar survival across all soil types. In contrast, Goupia glabra, Qualea rosea, Jacaranda co- paia, and Sextonia rubra suffered greater mortality in white sand and midslope sites than in other soils, while Recordoxylon speciosum, Virola michelii, and Eperua falcata suffered greater mortality in the swamp forest soils. Species also responded significantly differently to gaps (Table 2). Although most species responded positively to gaps, D. guianensis and E. grandiflora experienced only slight survival advantages in gap sites (Appendix B: Fig. B1). At the other extreme, G. glabra and $J$. copaia survived almost exclusively in gap sites, and survival of $Q$. rosea and $R$. speciosum almost doubled in gap relative to understory sites.

For seedling relative height growth, light transmission had the strongest effect among covariates for the ANCOVA model (Table 3). Nevertheless, the inclusion of light in the model did not eliminate the significant effect of gaps, suggesting that growth responds to unmeasured aspects of gaps, as well as to light availability and the microclimatic conditions with which it is correlated. Neither soil moisture nor soil phosphate were significantly correlated with seedling height overall, although soil phosphate was significantly positively correlated with seedling height in later seedling stages, resulting in a significant interaction with the repeated measure (Table 3).

Height differences between gap and understory sites varied widely among species. D. guianensis and E. falcata increased in height by nearly $50 \%$ in gaps relative 
TABLE 3. Summary table of a repeated-measures ANCOVA for seedling height in the field experiment.

\begin{tabular}{|c|c|c|c|}
\hline Source & $\mathrm{df}$ & MSE & $F$ \\
\hline \multicolumn{4}{|l|}{ Between subjects } \\
\hline Light availability ( $\%$ full sun) & 1 & 8.09 & $21.5 * * *$ \\
\hline Soil $\mathrm{PO}_{4}-\mathrm{P}(\mathrm{mg} / \mathrm{kg})$ & 1 & 0.61 & 1.61 \\
\hline Soil moisture $\left(\mathrm{m}^{3} / \mathrm{m}^{3}\right)$ & 1 & 0.58 & 1.54 \\
\hline Species & 8 & 150.8 & $400.5 * * *$ \\
\hline Gap & 1 & 14.5 & $38.5 * * *$ \\
\hline Soil type & 3 & 0.58 & 1.55 \\
\hline Species $\times$ gap & 8 & 2.88 & $7.66 * * *$ \\
\hline Species $\times$ soil type & 24 & 0.44 & 1.16 \\
\hline Gap $\times$ soil type & 3 & 0.81 & 2.16 \\
\hline Species $\times$ gap $\times$ soil type & 24 & 0.33 & 0.87 \\
\hline Error & 884 & 0.38 & \\
\hline \multicolumn{4}{|l|}{ Within subjects } \\
\hline Months & 7 & 0.63 & $17.0 * * *$ \\
\hline Months $\times$ light & 7 & 2.09 & $56.1 * * *$ \\
\hline Months $\times$ soil $\mathrm{PO}_{4}-\mathrm{P}$ & 7 & 0.13 & $3.50 * * *$ \\
\hline Months $\times$ soil moisture & 7 & 0.03 & 0.73 \\
\hline Months $\times$ species & 56 & 0.18 & $4.82 * * *$ \\
\hline Months $\times$ gap & 7 & 2.05 & $55.0 * * *$ \\
\hline Months $\times$ soil type & 21 & 0.11 & $2.81 * * *$ \\
\hline Months $\times$ species $\times$ gap & 56 & 0.17 & $4.47 * * *$ \\
\hline Months $\times$ species $\times$ soil type & 168 & 0.04 & 1.16 \\
\hline Months $\times$ gap $\times$ soil type & 21 & 0.10 & $2.80 * * *$ \\
\hline Months $\times$ species $\times$ gap $\times$ soil type & 168 & 0.03 & 0.69 \\
\hline Error & 6188 & 0.04 & \\
\hline
\end{tabular}

Notes: Factors include the effects of species ( $n=9$ species), light (gap, understory), and soil type (plateau, slope, white sand, and swamp). Data are seedling height of all individuals surviving to eight census dates to 54 months, ln-transformed for the analysis. Environmental factors measured at each site (summarized in Table 2) were included in the model as covariates. *** $P<0.001$

to understory sites, nearly doubling their relative growth rates (Appendix B: Fig. B2). At the other extreme, $S$. rubra height did not respond to gaps and had the lowest relative growth rate overall.

\section{Pairwise performance contrasts and rank reversals}

Table 4 illustrates performance contrasts among all species pairs in the experimental community. The upper part of the table indicates the number of cases out of 32 possible in which a species (row or column) significantly outperformed the other species. None of the nine species outperformed each of the other eight species in even one of the 32 contrasting situations. Four species were significantly outperformed by most other species. (Q. rosea and J. copaia never outperformed each other, but $Q$. rosea was outperformed by all other species at least once.) Four other species (D. guianensis, V. michelii, E. grandiflora, and E. falcata) were rarely outperformed.

Of the 36 species pairs, 15 exhibited at least one kind of trade-off, defined as a rank reversal such that each species significantly outperformed the other under at least one situation (Table 4). Only three species pairs exhibited strict microhabitat trade-offs, in which the rank reversal occurred between microhabitats for the same fitness component and the same ontogenetic stage, even though significant statistical interactions between species and microhabitat were detected for both survival and growth rate (Tables 2 and 3). For example, although G. glabra, J. copaia, and $Q$. rosea all exhibited much greater survival in gap than understory sites, this augmentation in survival did not reverse their survival ranking relative to the other six species for which survival was higher in both gap and understory sites. As a result, these three species were consistently ranked among the three lowest for survival (Table 4). In fact, survival rankings were strongly conserved in gap-understory contrasts across all four soil types at both early and later ontogenetic stages. Similar patterns occurred for the magnitude, but not the qualitative outcome, of growth response to microhabitat (Table 4).

Only two species pairs exhibited strict fitness component trade-offs (within a microhabitat for the same stage); respectively, $R$. speciosum and E. grandiflora survived better initially but grew more slowly than $J$. copaia or G. glabra in gap sand or slope plots (Table 4). Eight species pairs had fitness component trade-offs across microhabitat types that involved lower understory survival but higher gap RGR of G. glabra or $J$. copaia vs. one of the seven other species (Table 4).

Only one species pair showed a strict ontogenetic trade-off; in understory plateau plots E. grandiflora grew faster initially than $V$. michelii, but this reversed in the later period (Table 4). Seven species pairs showed microhabitat $\times$ ontogenetic trade-offs in which 
the better performing species (for survival or RGR) switched between early and later parts of the experiment across microhabitats. This result is concordant with the highly significant repeated-measures term and its interactions with species for both survival and RGR (Tables 2 and 3). Ontogenetic rank reversals were most pronounced for RGR and were driven by increased RGR response in gaps for species with intermediate rankings in the earlier stage (Fig. 2). An additional five species pairs showed interactions between ontogenetic, microhabitat, and fitness component trade-offs (Table 4).

Fig. 2 illustrates how many performance rank shifts occurred as interactions among microhabitat types, fitness components, and ontogenetic stages. For example, in microhabitats where soil resources are least limiting (swamp forest soils), species with high RGR in gap sites had the lowest survival in understory sites (Fig. 2). However, in microhabitats where soil resources are most limiting (midslope soils), no consistent pattern existed. The apparent explanation is that two species, $Q$. rosea and $S$. rubra, experience reduced understory survival in midslope soils, with no accompanying increase in gap RGR (Appendix B). Furthermore, the overall shifts with ontogeny dissolved the fitness component trade-offs between gap and understory microhabitats that were apparent in the early stage in all but the swamp soils. In most microhabitats, S. rubra retained its low rankings for both survival and RGR, yet shifts among the other species resulted in some ontogenetic trade-offs in which species ranked highest for a fitness component in the early stage were ranked lower in the later stage (Fig. 2).

Twenty-one of 36 species pairs showed no evidence of performance trade-offs of any kind. In two of these cases (J. copaialQ. rosea; E. grandifloralE. falcata), coexistence might still be promoted because neither species ever outperformed the other (Table 4). One species consistently outperformed the other in the 19 remaining cases, 12 of which involved one of the four highest performing species outperforming J. copaia, Q. rosea, or S. rubra.

\section{DISCUSSION}

To evaluate the relative importance of microhabitat, fitness component, and ontogenetic trade-offs, we discuss the evidence for each of these in turn, as well as the interactions among them. We then summarize the implications for the potential contribution of trade-offs to the community structure of tropical forests.

\section{Microhabitat trade-offs}

The extent to which microhabitat trade-offs contribute to coexistence has been the subject of much recent debate (Hubbell et al. 1999, Brokaw and Busing 2000). One point of contention has been the way in which rank reversals should be measured and interpreted. Sack and Grubb $(2001,2003)$ have suggested that any difference between species in the reaction norm of a fitness component along an "ecologically relevant" resource gradient (e.g., "crossovers" between species of the functions relating RGR to light) be considered evidence for a performance rank reversal. However, as Kitajima and Bolker (2003) correctly point out, such an analysis often requires extrapolation of the shape of the reaction norm to resource levels for which no data exist, and thus may inflate the actual number of rank reversals occurring between two species (for which no empirical rank reversal has been observed). Our study comprised a large proportion of the full resource gradients to which these species are exposed, and represents similar gradients to other lowland tropical forests. The size of the single-treefall gaps we chose was similar to $\sim 70 \%$ of gaps reported in this and other tropical forests (Hubbell et al. 1999, Baraloto 2001). Furthermore, the range of phosphate values exhibited across all soil types is similar to gradients found in other lowland tropical forests on oxisols or ultisols, where mean extractable phosphate levels $<3 \mathrm{mg} / \mathrm{kg}$ are common, yet microsites with as much as $30 \mathrm{mg} / \mathrm{kg}$ are occasionally reported (Vitousek and Denslow 1986, 1987, Burslem et al. 1994, Raaimakers 1994). Nevertheless, we found few rank reversals for RGR or survival across microhabitats for a given ontogenetic stage. Only 2 out of the 36 species pairs exhibited strict microhabitat trade-offs (Table 4), strongly supporting the argument that rank reversals occur infrequently with respect to microhabitat and by themselves contribute little to community organization in tropical forests (Kitajima and Bolker 2003).

Furthermore, the observed exchanges in rankings were restricted almost exclusively to the gap/understory contrast rather than among soil types. In fact, only one of the two species-pair microhabitat trade-offs (late stage survival between $D$. guianensis winning swamp gaps and $V$. michelii winning plateau gaps; Table 4) occurred between soil types without any gap-understory contrast. This case was likely due to extensive herbivory suffered by $V$. michelii in the swamp forest gaps (C. Baraloto, personal observation) rather than response to soil type per se. Fine et al. (2004) show that soil type effects on seedling performance of 20 Peruvian tree species are mitigated in part by differential herbivore pressures between white sand and clay soil types. Further research will be necessary to determine the extent to which herbivore pressure varies across microhabitats, and the potential consequences of herbivore suppression for microhabitat specialization in different tropical forests.

In contrast with a recent field experiment in Malaysian forests that found differential species growth response to soil type (Palmiotto et al. 2004), we found little evidence for differential performance across soil types differing in soil moisture and phosphate availability. We suggest that these edaphic factors may play a subordinate role to light availability in filtering spe- 
TABLE 4. Pairwise performance contrasts among the nine species in the experiment across 32 field situations.

\begin{tabular}{|c|c|c|c|c|c|}
\hline Species & G. glabra & J. copaia & Q. rosea & R. speciosum & D. guianensis \\
\hline G. glabra & & 2,1 & 2,1 & 2,4 & 2,6 \\
\hline J. copaia & $\mathrm{M} \times \mathrm{O}$ & & 0,0 & 1,5 & 0,4 \\
\hline Q. rosea & $\mathrm{M} \times \mathrm{F}$ & none $\dagger$ & & 0,4 & 0,10 \\
\hline R. speciosum & $\mathrm{M} \times \mathrm{F}, \mathrm{M} \times \mathrm{F} \times \mathrm{O}$ & $\mathrm{F}, \mathrm{M} \times \mathrm{F}, \mathrm{M} \times \mathrm{F} \times \mathrm{O}$ & none & & 2,3 \\
\hline D. guianensis & $\mathrm{M} \times \mathrm{F}, \mathrm{M} \times \mathrm{F} \times \mathrm{O}$ & none & none & $\mathrm{M}, \mathrm{M} \times \mathrm{O}, \mathrm{M} \times \mathrm{F} \times \mathrm{O}$ & \\
\hline S. rubra & $\mathrm{M} \times \mathrm{F}$ & none & none & none & none \\
\hline V. michelii & $\mathrm{M} \times \mathrm{O}, \mathrm{M} \times \mathrm{F} \times \mathrm{O}$ & none & none & none & $\mathrm{M}, \mathrm{M} \times \mathrm{O}, \mathrm{M} \times \mathrm{F}$ \\
\hline E. falcata & $\mathrm{M} \times \mathrm{F}, \mathrm{M} \times \mathrm{F} \times \mathrm{O}$ & none & none & $\mathrm{M}, \mathrm{M} \times \mathrm{O}, \mathrm{M} \times \mathrm{F} \times \mathrm{O}$ & $\mathrm{F} \times \mathrm{O}$ \\
\hline E. grandiflora & $\mathrm{F}, \mathrm{M} \times \mathrm{F}, \mathrm{M} \times \mathrm{F} \times \mathrm{O}$ & none & none & none & none \\
\hline
\end{tabular}

Notes: The field situations were: two ontogenetic stages $\times$ two fitness components $\times$ eight microhabitats; see Methods for details). The upper part of the matrix shows the number of situations in which each species (row, column) exhibited significantly higher performance across the six replicate plots, after Wilcoxon's $Z$ statistic with Bonferroni-corrected $P<0.05$. Tradeoffs between each species pair are indicated in the lower part of the matrix as cases when performance rankings significantly reversed across microhabitats (M) within any fitness component or stage, between the fitness components survival and RGR (F) within any stage or microhabitat, between ontogenetic stages (O) within any component, or as interactions among these types.

$\dagger$ Neither species had higher performance under any situation.

cies at the seedling stage in this tropical forest. This result moderates many of the conclusions drawn from pot experiments in this and other tropical forests in which significant interspecific differences in RGR have been found in response to soil nutrient and moisture manipulations (Huante et al. 1995, Burslem 1996, Raaimakers and Lambers 1996; C. Baraloto, D. Bonal, and D. E. Goldberg, unpublished data).

\section{Fitness component trade-offs}

Microhabitat does appear to play a significant role by interacting to create trade-offs between the fitness components of survival and RGR. Eight species pairs showed rank reversals between RGR and survival across microhabitats at the same ontogenetic stage (Table 4). Seven of these fitness component trade-offs were between RGR in gap plots (higher in the small-seeded heliophilic G. glabra or J. copaia) and survival in understory plots (higher in one of six other larger seeded species).

For the nine-species community, a negative trend exists between RGR in gaps and survival in the understory for the early seedling stage across all soil types ( $r^{2}=0.13, P=0.03$ ), lending some support to the notion that shade tolerance involves a general tradeoff between survival in the shade and rapid growth in the "sun" (Kitajima 1994, 2002, Davies 2001, Dalling and Hubbell 2002). However, this weak negative relationship was strongest in swamp soils where soil resources are least limiting, and did not occur in midslope soils where both mineral nutrients and water are most limiting (Fig. 2). The outcome of fitness component trade-offs thus appears to depend not only on gap microhabitats as demonstrated by Kitajima (1994), but also on interactions between gaps and soil conditions. Several authors have recently noted the lack of investigation of tropical tree seedling response to belowground resources in the field (e.g., Bloor 2003). Here we underline the importance of testing for these differences across light environments.

\section{Ontogenetic trade-offs}

A highly significant contribution of this study is the demonstration of rank reversals that can occur between ontogenetic stages, especially across some microhabitats and/or fitness components. Thirteen of the 15 species pairs exhibiting trade-offs reversed rankings in some measure of performance between the early and later stages of the experiment (Table 4). Seven of these switches occurred for a given fitness component; for three species pairs, reversals in RGR between early and later stages were the only evidence for rank reversals that might permit these pairs to coexist. Clark and Clark (1992) provided evidence for similar ontogenetic tradeoffs among nine Costa Rican tree species at sapling and subadult stages, and they made a strong case for examining microhabitat preferences and performance hierarchies at all life history stages. Svenning (2000) also found ontogenetic differences in light microsite occupation among 7 of 20 understory species in Yasuni, Ecuador. And Davies (2001) observed shifts in both growth and mortality rates with tree size among 11 species of Bornean Macaranga. Yet most studies examining performance rankings among tropical tree seedlings have focused on short-term experiments to detect crossovers. While this may be necessary to avoid pot limitation in shadehouse experiments (e.g., Bloor 2003), more field experiments will be necessary to determine how species rankings may shift over the tens of years required in many cases for successful adult recruitment (Clark and Clark 1992).

\section{Performance trade-offs and community structure}

Our results demonstrate that almost half of the species pairs in this nine-species community meet the requirement of species performance trade-offs necessary to promote coexistence (see Table 4). However, whether these trade-offs alone are sufficient for coexistence depends on population dynamics phenomena, including the distribution of these microhabitats in space and 
TABle 4. Extended.

\begin{tabular}{clcc}
\hline \hline S. rubra & V. michelii & E. falcata & E. grandiflora \\
\hline 2,2 & 2,4 & 1,8 & 2,8 \\
1,0 & 0,7 & 0,10 & 0,7 \\
0,1 & 0,2 & 0,7 & 0,7 \\
9,0 & 1,0 & 2,6 & 0,3 \\
9,0 & 5,2 & 1,1 & 0,1 \\
& 0,7 & 0,12 & 0,9 \\
none & & 1,4 & 2,2 \\
none & $\mathrm{M} \times \mathrm{O}$ & none $\dagger$ & 0,0 \\
none & $\mathrm{O}, \mathrm{M} \times \mathrm{O}$ & & \\
\hline
\end{tabular}

time, and across scales. In particular, understanding the contribution of fitness component and ontogenetic type trade-offs to species coexistence will require the development of theoretical models that integrate individual fitness across the entire life cycle, especially for long-lived organisms such as tropical trees.

Coexistence might also be promoted if species are ecologically equivalent; that is, neither species outperforms the other under any situation and are thus ecologically neutral (Hubbell 2001, Chave 2004). Remarkably, only two species pairs we studied were "ecologically-equivalent" in performance such that neither outperformed the other under any experimental situation.

Our study represents a multidimensional example of scenario 2 in Fig. 1. Nineteen species pairs comprise consistent superior and inferior performers, suggesting that some alternative mechanism contributes to their coexistence. It has been suggested that dispersal limitation may be more important to structuring tropical forest tree communities than performance differences because potential competitors rarely encounter one another in the field (Coomes and Grubb 2003). Although it is unlikely that all nine species encounter one another in the same $2.5-\mathrm{m}^{2}$ area, as they did in the experimental plots, the focal species are all common and do co-occur frequently as seedlings (Baraloto and Goldberg 2004). Still, the initial planting density of our experiment, while within the natural range observed in this forest, was rather high. Wright (2002) asserts that low densities in the forest understory may promote species coexistence by limiting competitive interactions. However, such a scenario of low density occurs rarely at Paracou, where woody plant juvenile densities, although extremely variable, are on average more than twice those described in other neotropical forests.

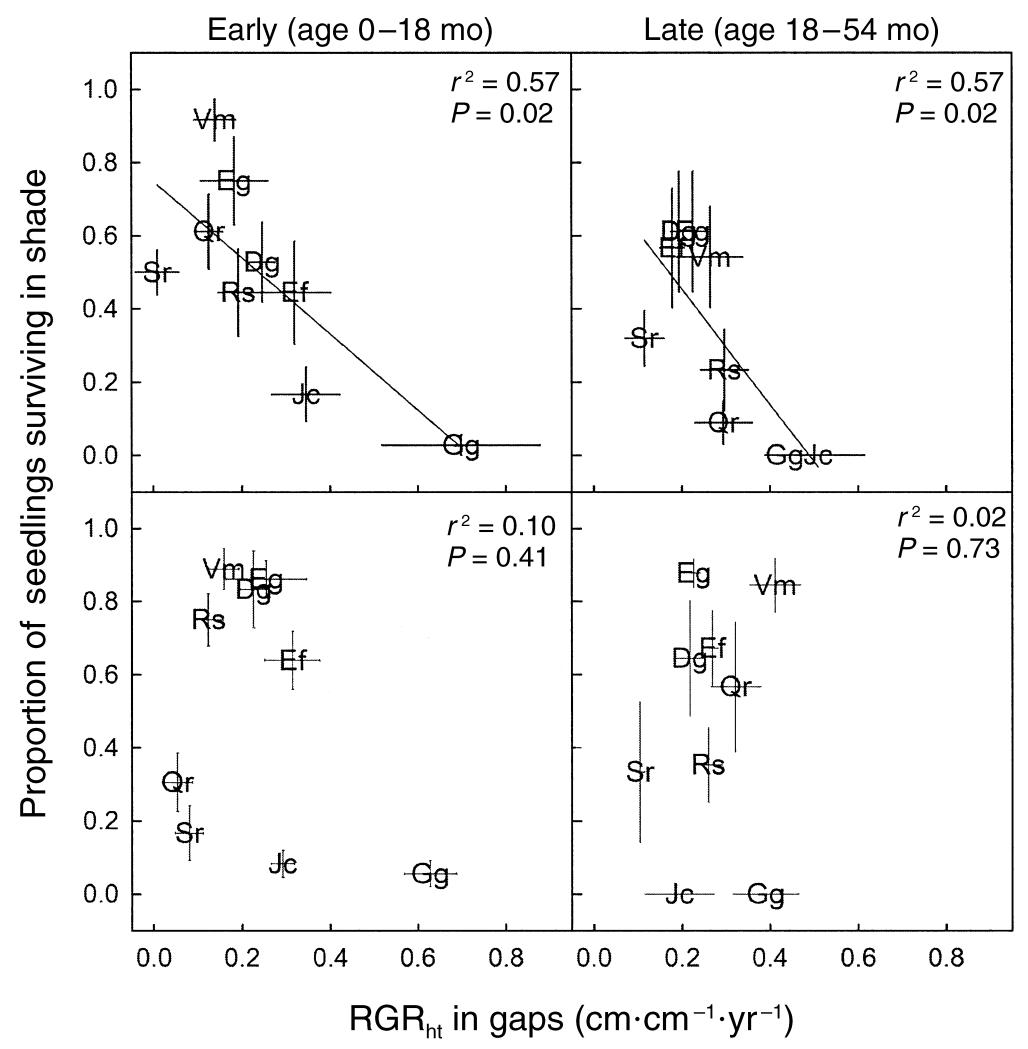

FIG. 2. Interactions between microhabitat, fitness component, and ontogenetic trade-offs across the nine-species experimental community. Panels depict survival in understory microhabitats vs. RGR (relative growth rate) in gap microhabitats in rich, humid swamp (top panels) and poor, dry midslope soil microhabitats (bottom panels). Panels on the left side indicate early seedling stage, from transplanted germinant to 18 months of age. Panels on the right side indicate the later seedling stage, from 18 to 54 months of age. Symbols are the initials of the specific epithet for each focal species (see Table 1). Results of linear regressions between the two fitness components are shown within each panel. 
Harms et al. (2004) report densities for seedlings 10$50 \mathrm{~cm}$ in height from 1.1 seedlings $/ \mathrm{m}^{2}$ at La Selva, Costa Rica, to 6.4 seedlings $/ \mathrm{m}^{2}$ at Cocha; in natural forest at Paracou, the average density for the same size class is 15.2 seedlings $/ \mathrm{m}^{2}$ (C. Baraloto and J.-F. Molino, unpublished data).

Even when species pairs occur at the same site, particular site factors might be more important for performance than the coarse microhabitat groups we established. In our experiment, the analyses to determine pairwise reversals in species performance grouped the plots within particular microhabitat types, potentially masking cases when species survived best or grew fastest in a particular site. In fact, if one were to choose a winning species for each plot based on the largest surviving seedling at the last census date, eight of the nine species would win in at least one of the 48 plots because of differential growth and survival through the five years of the experiment.

Coexistence might also be promoted by ontogenetic trade-offs at subsequent life history stages. The ontogenetic shifts we describe here represent a brief interval in the life cycle of these long-lived perennial organisms, and ontogenetic rank reversals are likely to continue at subsequent stages. Recent evidence for these same nine species in French Guiana supports this assertion. More than 2000 saplings $(>150 \mathrm{~cm}$ in height and $<10 \mathrm{~cm} \mathrm{dbh}$ ) of the nine species have been followed since 1992 in 768 plots of $50 \mathrm{~m}^{2}$ (C. Baraloto, unpublished data). The three species that were consistently outperformed as seedlings provide relevant examples. S. rubra and $Q$. rosea, which here had among the lowest RGR in most microhabitats at both early and later seedling stages, rank second and third for sapling growth rate. And J. copaia saplings grew faster than four of the five species that outperformed it at the seedling stage. In concert with the results of Clark and Clark (1992), our study suggests that an understanding of performance trade-offs for long-lived perennials such as tropical trees will require long-term data across multiple life history stages for some well-chosen focal species (Grubb 1996).

Further research will be necessary to elucidate which trade-offs are most important in structuring tropical tree communities. Studies such as this one must be integrated with data on phenology and fecundity, as well as studies on dispersal and seed and seedling predation, to analyze the contribution of trade-offs across the entire life cycle. Furthermore, other functional traits typically included in ecophysiological studies (carbon assimilation, stomatal conductance for water vapor, water use efficiency, and leaf nutrient concentrations), could be integrated in focal species choice and analysis of experiments to better understand the mechanisms underlying the performance trade-offs observed here. We stress that continued monitoring of experiments and plots for more than five years will be necessary to determine if and how performance hierarchies change with subsequent ontogenetic stages. Most importantly, further theoretical work with models structuring both environmental heterogeneity and population structure will be necessary to determine whether the necessary trade-offs we describe here are indeed sufficient for coexistence.

\section{ACKNOWLEDGMENTS}

This project was conducted with financial support from the University of Michigan (UM) and the French ECOFOR group. We thank CIRAD-Forêt for permission to conduct research in the Paracou reserve, and Silvolab-Guyane/UMR EcoFoG for the use of facilities in Kourou. T. Perot and F. Dada helped establish the exclosures in the field, and P.-M. Forget and S. Jésel helped with inventories. D. Zak, W. Holmes, and staff in the Laboratory of Terrestrial Ecology at SNRE-UM provided useful assistance and input regarding soil analyses. C. Baraloto is grateful to the Department of Botany at the University of Florida, where he was in residence during completion of the manuscript. We thank L. Curran, P. Fine, P.-M. Forget, P. Grubb, K. Harms, K. Kitajima, T. Miller, B. Shipley, and three anonymous reviewers for useful comments on earlier drafts of this manuscript.

\section{Literature Cited}

Armstrong, R. A., and R. McGehee. 1980. Competitive exclusion. American Naturalist 115:151-170.

Baraloto, C. 2001. Trade-offs between neotropical tree seedling traits and performance in contrasting environments. Dissertation. University of Michigan, Ann Arbor, Michigan, USA.

Baraloto, C., and D. E. Goldberg. 2004. Microhabitat associations and seedling bank dynamics in a neotropical forest. Oecologia 141:701-712.

Bloor, J. M. G. 2003. Light responses of shade-tolerant tropical tree species in north-east Queensland: a comparison of forest- and shadehouse-grown seedlings. Journal of Tropical Ecology 19:163-170.

Bonal, D., T. S. Barigah, A. Granier, and J.-M. Guehl. $2000 a$. Late stage canopy tree species with extremely low d13C and high stomatal sensitivity to seasonal soil drought in the tropical rainforest of French Guiana. Plant Cell and Environment 23:445-459.

Bonal, D., D. Sabatier, P. Montpied, D. Tremeaux, and J.-M. Guehl. 2000b. Interspecific variability of d13C among canopy trees in rainforests of French Guiana: functional groups and canopy integration. Oecologia 124:454-468.

Brokaw, N., and R. T. Busing. 2000. Niche versus chance and tree diversity in forest gaps. Trends in Ecology and Evolution 15:183-188.

Burslem, D. F. R. P. 1996. Differential response to nutrients, shade, and drought among tree seedlings of lowland tropical forest in Singapore. Pages 109-139 in M. D. Swaine, editor. The ecology of tropical forest tree seedlings. UNESCO/Parthenon, Paris, France.

Burslem, D. F. R. P., I. M. Turner, and P. J. Grubb. 1994. Mineral nutrient status of coastal hill dipterocarp forest and Adinandra belukar in Singapore: bioassays of nutrient limitation. Journal of Tropical Ecology 10:579-599.

Canham, C. D., and P. L. Marks. 1985. The response of woody plants to disturbance: patterns of establishment and growth. Pages 197-216 in S. T. A. Pickett and P. S. White, editors. The ecology of natural disturbance and patch dynamics. Academic Press, New York, New York, USA.

Chase, J. M., and M. A. Leibold. 2003. Ecological niches. University of Chicago Press, Chicago, Illinois, USA.

Chave, J. 2004. Neutral theory and community ecology. Ecology Letters 7:241-253. 
Chesson, P. L. 1985. Coexistence of competitors in spatially and temporally varying environments: a look at the combined effects of different sorts of variability. Theoretical Population Biology 28:263-287.

Chesson, P. L. 2000. Mechanisms of maintenance of species diversity. Annual Review of Ecology and Systematics 31: 343-366.

Clark, D. A., and D. B. Clark. 1992. Life history diversity of canopy and emergent trees in a neotropical rain forest. Ecological Monographs 62:315-344.

Coomes, D. A., and P. J. Grubb. 2003. Colonization, tolerance, competition and seed-size variation within functional groups. Trends in Ecology and Evolution 86:286-291.

Dalling, J. W., and S. P. Hubbell. 2002. Seed size, growth rate and gap microsite conditions as determinants of recruitment success for pioneer species. Journal of Ecology 90:557-568.

Davies, S. J. 2001. Tree mortality and growth in 11 sympatric Macaranga species in Borneo. Ecology 82:920-932.

Fine, P. V. A., I. Mesones, and P. D. Coley. 2004. Herbivores promote habitat specialization by trees in Amazonian forests. Science 305:663-665.

Givnish, T. J. 1988. Adaptations to sun and shade: a whole plant perspective. Australian Journal of Plant Physiology 15:63-92.

Grime, J. P. 1977. Evidence for the existence of three primary strategies in plants and its relevance to ecological and evolutionary theory. American Naturalist 111:1169-1194.

Grime, J. P. 1979. Plant strategies and vegetation processes. Wiley, Chichester, UK.

Grubb, P. J. 1977. The maintenance of species richness in plant communities: the importance of the regeneration niche. Biological Reviews of the Cambridge Philosophical Society 52:107-145.

Grubb, P. J. 1996. Rainforest dynamics: the need for new paradigms. Pages 215-233 in D. S. Edwards, editor. Tropical rainforest research-current issues. Kluwer Academic, Amsterdam, The Netherlands.

Grubb, P. J., and D. J. Metcalfe. 1996. Adaptation and inertia in the Australian tropical lowland rain-forest flora: contradictory trends in intergeneric and intrageneric comparisons of seed size in relation to light demand. Functional Ecology 10:512-520.

Hammond, D. S., and V. K. Brown. 1995. Seed size of woody plants in relation to disturbance, dispersal, soil type in wet neotropical forests. Ecology 76:2544-2561.

Harms, K. E., J. S. Powers, and R. A. Montgomery. 2004. Variation in small sapling density, understory cover, and resource availability in four neotropical forests. Biotropica 36:40-51.

Huante, P., E. Rincon, and F. S. Chapin, III. 1995. Responses to phosphorus of contrasting successional tree-seedling species from the tropical deciduous forest of Mexico. Functional Ecology 9:760-766.

Hubbell, S. 2001. A unified neutral theory of biodiversity and biogeography. Princeton University Press, Princeton, New Jersey, USA.

Hubbell, S. P., R. B. Foster, S. T. O’Brien, K. E. Harms, R. Condit, B. Wechsler, S. J. Wright, and S. L. deLao. 1999. Light-cap disturbances, recruitment limitation, and tree diversity in a neotropical forest. Science 283:554-557.

Hunt, R. 1978. Plant growth analysis. Edward Arnold, London, UK.

Huston, M. A. 1994. Biological diversity. The coexistence of species on changing landscapes. Cambridge University Press, Cambridge, UK

Kitajima, K. 1994. Relative importance of photosynthetic traits and allocation patterns as correlates of seedling shade tolerance of 13 tropical trees. Oecologia 98:419-428.
Kitajima, K. 2002. Do shade-tolerant tropical tree seedlings depend longer on seed reserves? Functional growth analysis of three Bignoniaceae species. Functional Ecology 16: 433-444.

Kitajima, K., and B. M. Bolker. 2003. Testing performance rank reversals among coexisting species: crossover point irradiance analysis by Sack and Grubb (2001) and alternatives. Functional Ecology 17:276-281.

Kneitel, J. M., and J. M. Chase. 2004. Trade-offs in community ecology: linking spatial scales and species coexistence. Ecology Letters 7:69-80.

Latham, R. E. 1992. Co-occurring tree species change rank in seedling performance with resources varied experimentally. Ecology 73:2129-2144.

Lusk, C. H. 2004. Leaf area and growth of juvenile temperate evergreens in low light: species of contrasting shade tolerance change rank during ontogeny. Functional Ecology 18:820-828.

MacArthur, R. H., and R. Levins. 1964. Competition, habitat selection and character displacement. Proceedings of the National Academy of Sciences (USA) 51:1207-1210.

McConnaughay, K. D. M., and J. S. Coleman. 1999. Biomass allocation in plants: ontogeny or optimality? A test along three resource gradients. Ecology 80:2581-2593.

McPeek, M. A. 1996. Trade-offs, food web structure, and the coexistence of habitat specialists and generalists. American Naturalist 148:124-138.

Nicotra, A. B., R. L. Chazdon, and S. V. B. Iriarte. 1999. Spatial heterogeneity of light and woody seedling regeneration in tropical wet forests. Ecology 80:1908-1926.

Palmiotto, P. A., S. J. Davies, K. A. Vogt, M. A. Ashton, D. J. Vogt, and P. S. Ashton. 2004. Soil-related habitat specialization in dipterocarp rain forest tree species in Borneo. Journal of Ecology 92:609-623.

Poorter, L. 1999. Growth responses of 15 rain-forest tree species to a light gradient: the relative importance of morphological and physiological traits. Functional Ecology 13: 396-410.

Raaimakers, D. 1994. Growth of tropical rain forest trees as dependent on phosphorus supply. Dissertation. University of Utrecht, Utrecht, The Netherlands.

Raaimakers, D., and H. Lambers. 1996. Response to phosphorus supply of tropical tree seedlings: a comparison between a pioneer species Tapirira obtusa and a climax species Lecythis corrugata. New Phytologist 132:97-102.

Ricklefs, R. E. 1977. Environmental heterogeneity and plant species diversity: a hypothesis. American Naturalist 111: 377-381.

Sack, L., and P. J. Grubb. 2001. Why do species of woody seedlings change rank in relative growth rate between low and high irradiance? Functional Ecology 15:145-154.

Sack, L., and P. J. Grubb. 2003. Crossovers in seedling relative growth rates between low and high irradiance: analyses and ecological potential (reply to Kitajima and Bolker 2003). Functional Ecology 17:281-287.

Sack, L., T. Maranon, and P. J. Grubb. 2002. Global allocation rules for patterns of biomass partitioning. Science 296: 1923.

Schiesari, L. 2004. Performance trade-offs across resource gradients in anuran larvae. Dissertation. University of Michigan, Ann Arbor, Michigan, USA.

Stearns, S. C. 1992. The evolution of life histories. Oxford University Press, Oxford, UK.

Suding, K. N., and D. Goldberg. 2001. Do disturbances alter competitive hierarchies? Mechanisms of change following gap creation. Ecology 82:2133-2149.

Svenning, J. C. 2000. Small canopy gaps influence plant distributions in the rain forest understory. Biotropica 32: 252-261. 
Tilman, D. 1982. Resource competition and community structure. Princeton University Press, Princeton, New Jersey, USA.

Tilman, D. 1988. Plant strategies and the structure and dynamics of plant communities. Princeton University Press, Princeton, New Jersey, USA.

Tilman, D. 1990. Constraints and trade-offs: toward a predictive theory of competition and succession. Oikos 58:315.

Tilman, D. 1994. Competition and biodiversity in spatially structured habitats. Ecology 75:2-16.

Vitousek, P. M., and J. S. Denslow. 1986. Nitrogen and phosphorus availability in treefall gaps of a lowland tropical rainforest. Journal of Ecology 74:1167-1178.
Vitousek, P. M., and J. S. Denslow. 1987. Differences in extractable phosphorus among soils of the La Selva Biological Station, Costa Rica. Biotropica 19:167-170.

Walters, M. B., and P. B. Reich. 1996. Are shade tolerance, survival, and growth linked? Low light and nitrogen effects on hardwood seedlings. Ecology 77:841-853.

Walters, M. B., and P. B. Reich. 1999. Low-light carbon balance and shade tolerance in the seedlings of woody plants: do winter deciduous and broad-leaved evergreen species differ? New Phytologist 143:143-154.

Wright, I. J., et al. 2004. The worldwide leaf economics spectrum. Nature 428:821-827.

Wright, S. J. 2002. Plant diversity in tropical forests: a review of mechanisms of species coexistence. Oecologia 130:114.

\section{APPENDIX A}

Plot environmental characteristics for tropical tree seedling experiments are available in ESA's Electronic Data Archive: Ecological Archives E086-129-A1.

\section{APPENDIX B}

Figures describing survival and growth of tropical tree seedlings are available in ESA's Electronic Data Archive: Ecological Archives E086-129-A2. 